\title{
The association between traumatic experiences and suicide attempt in patients treated at the Hospital de Pronto Socorro in Porto Alegre, Brazil
}

\author{
Cleonice Zatti, ${ }^{1}$ (D) Luciano Santos Pinto Guimarães, ${ }^{2}$ Mauro Soibelman, ${ }^{3}$ Márcia Rejane Semensato, ${ }^{1}$ \\ Andre Goettems Bastos, ${ }^{4}$ Vítor Crestani Calegaro, ${ }^{5}$ Lúcia Helena Machado Freitas ${ }^{1}$
}

\begin{abstract}
Objective: To analyze associations between attempted suicide and childhood trauma.

Methods: A seven month comparative case-control study (28 subjects - patients with suicide attempt; 56 controls - patients without suicide attempt). The following instruments were used: Childhood Trauma Questionnaire (CTQ), Mini International Neuropsychiatric Interview (MINI), and Medical Outcomes Study (MOS).

Results: The group with suicide attempt had significantly higher scores for some variables: emotional abuse $(p<0.001)$, physical abuse $(p<0.001)$, emotional neglect $(p<0.001)$, and physical neglect $(p$ $<0.001)$.

Conclusions: The results suggest that variables related to previous trauma may influence future suicide attempts. The adoption of preventive and therapeutic actions related to mistreatments during child development is a crucial factor in reduction of suicide risk.
\end{abstract}

Keywords: Childhood trauma, suicide attempt, psychological suffering, abuse, neglect.

\section{Introduction}

Suicide is a multi-causal problem for which, to date, no unified reference theory has been identified. It may be the result of a multifaceted interaction between biological, genetic, psychological, social, and cultural factors. Suicide behavior must be confronted as a public health problem. This is a broad task, because it involves training healthcare professionals for suicide risk (SR) detection as well as prevention and immediate treatment at the different levels of care. ${ }^{1,2}$ Suicide is an ancient and cross-cultural theme and remains a public health problem worldwide. ${ }^{3}$
One recent meta-analysis by Zatti et al. ${ }^{4}$ identified childhood trauma as a modifiable risk factor for lifetime suicide attempts. In that study, sexual and emotional abuse and physical neglect (considered psychological traumas) were associated with suicide attempt (SA). Other studies have reported findings pointing in the same direction. ${ }^{4}$

For example, Araújo ${ }^{5}$ studied suicidal behavior and childhood trauma in a database of 71,429 volunteers. The results illustrated an association between childhood emotional abuse and suicidal behavior and the author concluded that the most serious suicide attempts were associated with severe emotional abuse.

\footnotetext{
${ }^{1}$ Universidade Federal do Rio Grande do Sul (UFRGS), Porto Alegre, RS, Brazil. ${ }^{2}$ Hospital de Clínicas de Porto Alegre (HCPA), Porto Alegre, RS, Brazil. ${ }^{3}$ Hospital de Pronto Socorro, Porto Alegre, RS, Brazil. ${ }^{4}$ Contemporâneo: Instituto de Psicanálise e Transdisciplinaridade, Porto Alegre, RS, Brazil. ${ }^{5}$ Hospital Universitário de Santa Maria, Universidade Federal de Santa Maria (UFSM), Santa Maria, RS, Brazil.

Submitted Dec 12 2018, accepted for publication Jun 27 2019. Epub Mar 202020.

Suggested citation: Zatti C, Guimarães LSP, Soibelman M, Semensato MR, Bastos AG, Calegaro VC, et al. The association between traumatic experiences and suicide attempt in patients treated at the Hospital de Pronto Socorro in Porto Alegre, Brazil. Trends Psychiatry Psychother. 2020;42(1):64-73. http://dx.doi.org/10.1590/2237-6089-2018-0112
} 
The results of a study conducted in Rio de Janeiro with patients who attempted suicide showed a significant difference between cases and controls, with less social support among the suicide attempt cases analyzed. ${ }^{6}$ The present study is justified by the importance of investigating factors that can foment SR, such as traumatic experiences, mental illnesses, and loss of a significant relative. No data were found in the suicide attempt literature that directly relate recent losses with suicide attempt.

Considering the relevance of what has been outlined above, this study's main objective was to analyze the association between childhood trauma and suicide attempt in patients who needed hospital admission due to suicide attempts at the Hospital de Pronto Socorro (HPS) in Porto Alegre, Brazil. Secondary objectives were to assess the quality of the support networks of patients with and without $\mathrm{SA}$; to analyze the distribution of current suicide attempts over the days of the week; and to investigate associations between SA and significant dates. The study's main contribution is confirmation of the hypothesis that people with childhood traumas are at higher risk of attempted suicide.

\section{Method}

A case-control design was used in the study. Data were collected at the HPS in Porto Alegre, Brazil. The hospital is open 24 hours a day, offering urgent and emergency care for the entire population of Porto Alegre. Suicide attempt is one of several different urgent and emergency situations seen by the healthcare teams working at the HPS. The hospital is run according to SUS regulations (the SUS is Brazil's universal access public healthcare service) and it is the primary emergency service in the state of Rio Grande do Sul.

The number of participants was calculated using data published by Roy, ${ }^{7}$ who compared childhood trauma in groups of patients with and without suicide attempt. According to Roy's study, standard deviations (SD) for the variable "childhood trauma" were \pm 3.24 and \pm 5.07 in groups with and without SA respectively. To achieve $80 \%$ power and a significance level of $5 \%$, using a proportion of two controls per case, and with the goal of detecting a 3-point difference in total CTQ scores, we selected 84 participants ( 56 controls and 28 cases). The calculation was performed using WINPEPI Version 11.43. Participants were patients admitted via or seen in the HPS emergency room because of SA between August 20, 2015 and March 21, 2016.

The total number of suicide attempt cases seen during the study period was 37 . Nine cases were excluded from this study because of refusal to participate
( $n=4$ ) or because the patient was unresponsive to verbal interaction $(n=5)$. The participants were 28 cases and 56 controls. Controls were paired for gender and age and were recruited from patients seen on the same day as the cases for any reason other than suicide attempt and with no previous record of suicide attempt. The inclusion criteria stipulated that patients should be at least 18 years old, be able to reply to the questionnaires verbally, and be free from psychotic symptoms. They should also have agreed to participate in the study and provided signed informed consent to be included in the study. Patients were approached and data were collected at the bedside during the patients' time in hospital. Data were collected by a researcher with experience in suicidal behavior.

\section{Instruments}

Childhood Trauma Questionnaire (CTQ)

The CTQ is an adapted and validated tool that has been widely used to investigate the occurrence of abusive situations during childhood. ${ }^{8}$ The CTQ was developed by Bernstein et al., ${ }^{9}$ and translated and validated for Portuguese by Grassi-Oliveira et al. ${ }^{10}$ It is used to assess childhood trauma and abuse. This instrument can be administered to adolescents (12+ years of age) and adults. There are two versions of the CTQ: the first has 70 items and the second is a brief version with 28 items, with five-point Likert response scales. ${ }^{9}$ The CTQ investigates five dimensions of trauma in childhood: physical abuse, emotional abuse, sexual abuse, physical neglect, and emotional neglect. Scores range from 25 (absence of any trauma) to 125 (the maximum score when all traumas are present). ${ }^{8}$

\section{Medical Outcomes Study (MOS)}

This is a social support survey that evaluates the following dimensions: tangible support (provision of practical resources and material aid), affectionate support (physical demonstrations of love and affection), emotional support (capacity of the social network to satisfy individual needs related to emotional problems), informational support (counting on people who can offer guidance, information, and counsel), and positive social interaction (having people to relax and have fun with). The MOS was developed by Sherbourne \& Stewart, ${ }^{11}$ and translated and validated for Portuguese by Griep et al. ${ }^{12-14}$ Answers to items " $a$ " to " $t$ " are distributed along a five-point Likert scale. ${ }^{15}$

Mini International Neuropsychiatric Interview (MINI)

A short, standardized diagnostic interview (15-30 minutes). The Brazilian translation of version 5.0 for the DSM IV was used. ${ }^{16}$ 


\section{Sociodemographic questionnaire}

Used to collect general information such as gender, age, education, income, marital status, and occupation. As an additional item, the researcher also surveyed the medical team's clinical impression of the severity and lethality of each suicide attempt, case by case. The lethality of each attempt was scaled by the doctors as: 1, mild (no clinical complications, no admission required); 2, moderate (with clinical complications, requiring hospital admission); or 3 , serious (with critical complications, requiring Intensive Care Unit admission or special medical care).

\section{Ethical aspects}

All subjects were given the necessary clarifications. Procedures followed ethical standards, such as confidentiality of personal identity. Data collection tools were not administered to patients who refused to participate and their medical care at the hospital was unaffected.

The protocol for this study was approved by the research ethics committees at the Hospital de Clínicas de Porto Alegre (HCPA; protocol 150267; CAAE 44823315.1.0000.5327, opinion 1.111.108/2015) and the Porto Alegre Municipal Health Department (opinion $1.180 .317 / 2015)$. The committees were informed of the data collected in the project.

All participants were cared for by the HPS Psychology Service while in hospital, which also dealt with referrals for subsequent treatment as needed.

\section{Statistical analysis}

Attribute variables were expressed as absolute and relative frequencies. Quantitative variables were expressed as means and SD or medians and interquartile ranges, depending on the results of the Shapiro-Wilk test.

Groups were compared in terms of sociodemographic variables using the Chi-square test, the $t$ test for independent samples, or the Mann-Whitney test, depending on the types of variables and their distribution.

A generalized estimating equation (GEE) was used to compare means or proportions between groups. A correct analysis should consider paired subjects a single unit ( 1 case for 2 controls of the same gender and age). A covariance matrix with robust estimator was used with an exchangeable working correlation matrix for the GEE model. For the MOS questionnaire variables, a normal distribution and link identity function was used for the variable number of friends and relatives. Binomial distributions with logit link function were used for the variables recent loss of someone and childhood loss. The means of each variable on the CTQ questionnaire were compared for the factors 'group' and 'gender' and the interaction 'group $\times$ gender'. A gamma distribution with log link was used. The Bonferroni post-hoc test was conducted for analyses that exhibited statistical significance. ${ }^{17}$

For the MOS questionnaire, odds ratios were calculated using conditional logistic regression.

Some variables consisted of one item with multiple answers. These variables were analyzed in descriptive form. Analyses were performed using SPSS v.18 software. The level of significance adopted was 0.05 .

\section{Results}

Participants ( $n=84)$ had similar distribution with regards to gender $(\mathrm{M} / \mathrm{F}=46.4 \% / 53.6 \%)$ and mean age was 35.6 years $(S D=12.8)$. The mean number of years in education was $9.9(S D=4.6)$. Almost half of the participants were in a stable relationship (48.8\%). During the interviews, $61.9 \%$ said they were employed, $27.4 \%$ were unemployed, and $10.7 \%$ were retired or students (Table 1 ).

$26.2 \%$ of the subjects had a history of mental disorder; $56.3 \%$ reported at least one close family member with a history of mental disorder; $54.8 \%$ reported the loss of a significant other by death during their childhood; and $47 \%$ reported recent loss of a significant other by death. In $46.4 \%$, hospital admission coincided with a significant date, regardless of the reason for admission or emergency room visit. There were no statistically significant differences in sociodemographic characteristics.

When evaluated separately, the control group had only a $7.3 \%$ prevalence of previous mental disorder, while the case group had a $64.3 \%$ prevalence ( $p<$ 0.001 ). In the control group, $64.3 \%$ reported loss of a significant other during childhood, in contrast with $35.7 \%$ in the case group ( $p=0.025)$.

Sixteen of the case group subjects had a history of previous mental disorder; 62.5\% $(n=10)$ were on psychiatric treatment; $12.5 \%(n=2)$ were being seen by a psychologist, and $25 \%(n=4)$ were receiving both psychiatric and psychological treatment. Fourteen $(50 \%)$ of the subjects who attempted suicide $(n=28)$ had a record of previous suicide attempt and eight of these attempts were made in 2015-16.

The SA methods used were: ingestion of medication $(53 \%)$, cutting weapon/firearm $(3.1 \%)$, hanging $(6.3 \%)$, overdose $(6.3 \%)$, burning $(9.4 \%)$, jumping out of a moving car or from a great height $(9.4 \%)$, cuts to wrist and neck $(9.4 \%)$, and poisoning (lye, naphthalene, rat poison) (9.4\%). The total number of answers was 32 , because four SAs used more than one method. 
Seven people (28\%) wrote a suicide letter or left a message on smartphone apps and 13 people (46\%) tried to commit suicide in the presence of someone else. Four patients (14\%) reported that their chosen suicide method was not easy to acquire (for instance, buying rat poison or lye in agriculture/animal supply stores), while 24 subjects ( $85 \%$ ) described using means available in their own homes. Half of the participants (14 people, $50 \%$ ) reported that the index attempt was not their first suicide attempt and one subject reported eight suicide attempts over the course of his life.

The most frequent days of the week for SA were: Mondays and Tuesdays (43\%) and the most frequent time of day was in the morning, between 7:00 am and 10:00 am.

There were no statistically significance differences in CTQ results between men and women ( $\geq 0.05)$. Case and control groups had different means for the following variables: emotional abuse, physical abuse, emotional neglect, and physical neglect $(p<0.001$ for all variables), with case means always higher than control means (Table 2). Emotional abuse was the variable with the highest difference between means for cases and controls, followed by emotional neglect (5.3 and 5.1, respectively). Regarding gender, women presented significantly higher means than men for the variables: emotional abuse ( $p<0.001)$, physical abuse $(p=0.020)$, sexual abuse $(p=0.037)$, and emotional neglect $(p<0.001)$ (Table 2$)$.

In the case group, 23 participants $(82.1 \%)$ were classified as being at high risk for suicide, half of whom ( $n=14 ; 50 \%$ ) presented suicidal ideation at the time of the interview, while $18(64.3 \%)$ cases had a history of psychiatric disease in the family. Fifty-five people $(98.2 \%)$ in the control group had neither suicide risk nor suicidal ideation.

With regard to social support, for the whole sample, the mean number of family supporters was 3.4 (SD = 3.3) and mean number of close friends was 1.90 (SD $=2.8$ ). The control group had a mean of 6.6 support people, including both family and close friends, in contrast with 2.5 in the case group ( $p<0.001)$.

Still with relation to the MOS results, Table 3 shows the results for the dimensions: The control group presented means equal to or above 4.4 in all dimensions. In contrast, all means were below 3.4

Table 1 - Sociodemographic characteristics by group

\begin{tabular}{|c|c|c|c|}
\hline Variable & Controls $(n=56)$ & Cases $(n=28)$ & $\mathbf{p}$ \\
\hline \multicolumn{4}{|l|}{ Gender } \\
\hline Male & $26(46.4)$ & $13(46.4)$ & $>0.999$ \\
\hline Female & $30(53.6)$ & $15(53.6)$ & \\
\hline Age, mean (SD) $[\min -\max ]^{*}$ & $35.6(12.9)[19-66]$ & $35.4(12.8)[20-71]$ & 0.933 \\
\hline Years in education, mean (SD) $[\min -\max ]^{*}$ & $10.1(4.9)[1-25]$ & $9.7(4.0)[2-18]$ & 0.707 \\
\hline Income, Q2 (Q1-Q3) [min-max $]^{+}$ & $2.000(1.250-3.650)[233-33.000]$ & $2.000(1.360-3.500)[0-5.000]$ & 0.611 \\
\hline \multicolumn{4}{|l|}{ Marital status } \\
\hline Single & $20(35.7)$ & $10(35.7)$ & 0.177 \\
\hline Long-term relationship & $30(53.6)$ & $11(39.3)$ & \\
\hline Widowed & $1(1.8)$ & $0(0)$ & \\
\hline Separated & $5(8.9)$ & $7(25)$ & \\
\hline \multicolumn{4}{|l|}{ Occupation } \\
\hline Unemployed & $14(25.0)$ & $9(32.1)$ & 0.522 \\
\hline Employed & $37(66.1)$ & $15(53.6)$ & \\
\hline Retired or student & $5(8.9)$ & $4(14.3)$ & \\
\hline Prior psychiatric history & $4(7.1)$ & $18(64.3)$ & $<0.001$ \\
\hline Family psychiatric history & $27(48.2)$ & $18(64.3)$ & 0.246 \\
\hline History of significant loss in childhood & $36(64.3)$ & $10(35.7)$ & 0.025 \\
\hline Commemorative date near hospitalization & $29(51.8)$ & $10(37)$ & 0.305 \\
\hline Recent loss (death) of someone & $24(42.9)$ & $15(53.6)$ & 0.486 \\
\hline $\begin{array}{l}\text { Suicide attempt (in last } 3 \text { months), Q2 (Q1-Q3) } \\
\text { [min-max] }\end{array}$ & & $1(0-1)[0-3]$ & \\
\hline
\end{tabular}

Data presented as $\mathrm{n}(\%)$, unless otherwise specified.

Min-max = minimum-maximum; $\mathrm{Q}=$ quartile; $\mathrm{SD}=$ standard deviation.

$* t$ test for independent samples.

+ Brazilian reais (BRL) per month; Mann-Whitney $U$ test. 
Traumatic experiences and suicide attempt - Zatti et al.

Table 2 - Inter-group comparison of mean Childhood Trauma Questionnaire (CTQ) scores, using generalized estimating equation model analysis with gamma distribution

\begin{tabular}{|c|c|c|c|c|c|c|}
\hline Type of trauma & $\begin{array}{l}\text { Control } \\
\mathrm{n}=56\end{array}$ & $\begin{array}{c}\text { Case } \\
n=28\end{array}$ & $\begin{array}{c}\text { Total } \\
\mathbf{n}=84 \\
\end{array}$ & $\mathbf{p}_{\text {group }}$ & $\mathbf{P}_{\text {gender }}$ & $\mathbf{p}_{\text {interaction }}$ \\
\hline \multicolumn{7}{|l|}{ Emotional abuse } \\
\hline Male & $6.4(5.7-7.1)$ & $10.6(7.9-13.4)$ & $8.2(7.1-9.3)$ & & & \\
\hline Female & $9.0(7.1-10.9)$ & $15.6(12.5-18.7)$ & $11.8(10.1-13.6)$ & & & \\
\hline Total & $7.6(6.7-8.5)$ & $12.9(10.8-15.0)$ & & & & \\
\hline \multicolumn{7}{|l|}{ Physical abuse } \\
\hline Male & $5.9(5.4-6.4)$ & $10.2(7.2-13.3)$ & $7.8(6.6-9.0)$ & $<0.001$ & 0.020 & 0.672 \\
\hline Female & $7.9(6.5-9.4)$ & $12.5(9.6-15.3)$ & $9.9(8.6-11.3)$ & & & \\
\hline Total & $6.9(6.2-7.5)$ & $11.3(9.2-13.4)$ & & & & \\
\hline \multicolumn{7}{|l|}{ Sexual abuse } \\
\hline Male & $5.3(4.8-5.9)$ & $7.0(4.8-9.2)$ & $6.1(5.1-7.1)$ & 0.067 & 0.037 & 0.927 \\
\hline Female & $7.0(5.7-8.3)$ & $8.9(5.8-12.1)$ & $7.9(6.5-9.3)$ & & & \\
\hline Total & $6.1(5.5-6.8)$ & $7.9(6.0-9.8)$ & & & & \\
\hline \multicolumn{7}{|l|}{ Emotional neglect } \\
\hline Male & $7.0(5.8-8.1)$ & $10.8(9.0-12.5)$ & $8.7(7.5-9.8)$ & $<0.001$ & $<0.001$ & 0.676 \\
\hline Female & $10.1(8.1-12.2)$ & $17.0(13.7-20.3)$ & $13.1(11.6-14.6)$ & & & \\
\hline Total & $8.4(7.3-9.5)$ & $13.5(11.8-15.3)$ & & & & \\
\hline \multicolumn{7}{|l|}{ Physical neglect } \\
\hline Male & $7.1(6.7-7.5)$ & $8.3(6.6-10.0)$ & $7.7(6.9-8.5)$ & $<0.001$ & 0.064 & 0.162 \\
\hline Female & $7.5(6.5-8.6)$ & $10.8(8.9-12.7)$ & $9.0(7.8-10.2)$ & & & \\
\hline Total & $7.3(6.8-7.9)$ & $9.5(8.2-10.8)$ & & & & \\
\hline \multicolumn{7}{|l|}{ Total Score } \\
\hline Male & $31.7(29.9-33.7)$ & $46.9(39.7-55.4)$ & $38.6(35.2-42.3)$ & $<0.001$ & $<0.001$ & 0.731 \\
\hline Female & $41.6(35.6-48.6)$ & $64.8(54.8-76.7)$ & $51.9(46.6-57.8)$ & & & \\
\hline Total & $36.3(33.4-39.5)$ & $55.1(49.0-62.1)$ & & & & \\
\hline
\end{tabular}

Results expressed as mean ( $95 \%$ confidence interval).

$\mathrm{p}_{\text {group }}=\mathrm{p}$ value for the effect of the group; $\mathrm{p}_{\text {gender }}=\mathrm{p}$ value for the effect of gender; $\mathrm{p}_{\text {interaction }}=\mathrm{p}$ value for the effect of the group $\times$ gender interaction .

Table 3 - Previous/recent losses by death and Medical Outcomes Study (MOS) results: evaluation of dimensions

\begin{tabular}{|c|c|c|c|c|c|c|}
\hline & \multirow{2}{*}{$\begin{array}{c}\text { Control } \\
\text { Mean }(95 \% \mathrm{CI})\end{array}$} & \multirow{2}{*}{$\begin{array}{c}\text { Case } \\
\text { Mean }(95 \% \mathrm{CI})\end{array}$} & \multirow[b]{2}{*}{$\mathbf{p}$} & \multicolumn{3}{|c|}{ Conditional logistic regression } \\
\hline & & & & OR & $95 \% \mathrm{CI}$ & $\mathbf{p}$ \\
\hline Family+Close friends & $6.6(5.2-8.0)$ & $2.5(1.4-3.7)$ & $<0.001$ & 0.76 & $(0.64-0.91)$ & 0.003 \\
\hline MOS_Tangible & $4.6(4.4-4.8)$ & $3.4(2.9-3.8)$ & $<0.001$ & 0.20 & $(0.08-0.51)$ & $<0.001$ \\
\hline MOS_Affection & $4.6(4.4-4.8)$ & $3.4(2.9-3.9)$ & $<0.001$ & 0.31 & $(0.15-0.63)$ & $<0.001$ \\
\hline MOS_Emotional & $4.4(4.2-4.6)$ & $3.0(2.4-3.5)$ & $<0.001$ & 0.45 & $(0.29-0.69)$ & $<0.001$ \\
\hline MOS_Informational & $4.5(4.3-4.7)$ & $3.1(2.6-3.5)$ & $<0.001$ & 0.29 & $(0.15-0.57)$ & $<0.001$ \\
\hline MOS_PositiveSocialInteraction & $4.5(4.3-4.7)$ & $2.9(2.4-3.4)$ & $<0.001$ & 0.35 & $(0.20-0.62)$ & $<0.001$ \\
\hline MOS_f1_Aff_PosSoc & $4.5(4.3-4.7)$ & $3.1(2.6-3.6)$ & $<0.001$ & 0.30 & $(0.15-0.59)$ & $<0.001$ \\
\hline MOS_f2_Em_Inf & $4.5(4.2-4.7)$ & $3.0(2.5-3.5)$ & $<0.001$ & 0.37 & $(0.22-0.62)$ & $<0.001$ \\
\hline MOS_f3_Tangible & $4.6(4.4-4.8)$ & $3.4(2.9-3.8)$ & $<0.001$ & 0.20 & $(0.08-0.51)$ & $<0.001$ \\
\hline Recent loss of someone & $57.1(45.3-69.0)$ & $46.4(28.0-64.9)$ & 0.382 & 1.46 & $(0.62-3.45)$ & 0.388 \\
\hline History of childhood loss & $35.7(23.7-47.7)$ & $64.3(46.5-82.0)$ & 0.013 & 0.32 & $(0.12-0.84)$ & 0.021 \\
\hline Childhood + Recent loss* & $67.9(57.7-78.0)$ & $78.6(63.4-93.8)$ & 0.312 & 0.75 & $(0.42-1.34)$ & 0.334 \\
\hline
\end{tabular}

$95 \% \mathrm{CI}=95 \%$ confidence interval

All variables with normal distribution in the generalized estimating equation (GEE); * binomial distribution in the GEE. 
in the case group, presenting significant values in all dimensions ( $p<0.001)$.

As can be observed from the table, having an extra family member and/or friend to count on offers $24 \%$ protection against suicide risk and one additional point of tangible support is associated with $80 \%$ protection. One additional point of affectionate support offers $69 \%$ protection against risk of suicide attempt; emotional support provides 55\% ( $p<0.001)$; informational support provides $71 \%(p<0.001)$; and positive social interaction offers $65 \%$ protection. When combined, affectionate support and social interaction offer $70 \%$ protection ( $p<0.001$ ) with one additional point. Combining emotional support with informational support gives $63 \%$ ( $p<0.001)$.

Family history data is shown in Table 4. Forty-three subjects responded to a parallel investigation about adverse events, memories, or significant dates and 65\% (n $=28$ ) exhibited proximity between the date of admission and anniversaries of these items, whether related to the patients themselves or to a close family member.

Table 5 shows that 10 people admitted due to SA reported 11 events: $54.5 \%$ (6 events) related to anniversaries and $45.5 \%$ (5 events) related to holidays. In the control group, 29 people reported 32 events: $68.8 \%$ (22 events) were anniversaries and 15.6\% (5 events) were holidays.

An additional investigation asked the medical team to give their impression of the seriousness and lethality of the SA. They classified $32 \%(n=9)$ of the SA as 'Mild', 18\% $(n=5)$ as 'Moderate', and 50\% ( $n=18)$ as 'Serious'. Most of the cases (93\%, $n=26$ ) believed that their self-destructive act had caused some kind of emotional impact on a family member or friend.

Table 4 - Family psychiatric disorders

\begin{tabular}{lcc}
\hline & Control & Case \\
\hline Relationship & & \\
Mother & $11(29.7)$ & $8(28.6)$ \\
Father & $10(27.0)$ & $8(28.6)$ \\
Child & $4(10.8)$ & $3(10.7)$ \\
Sibling & $12(32.4)$ & $9(32.1)$ \\
Total responses & $37(100)$ & $28(100)$ \\
Total subjects & 27 & 18 \\
Type of disorder* & & \\
Depression & $16(8.7)$ & $11(10.8)$ \\
Suicide attempt & $4(2.2)$ & $8(7.8)$ \\
Suicide & $2(1.1)$ & 0 \\
Bipolar disorder & $1(0.5)$ & $2(2)$ \\
Alcohol problems & $14(7.6)$ & $12(11.8)$ \\
Drug problems & $9(4.9)$ & $7(6.9)$ \\
Psychiatric hospitalization & $2(1.1)$ & 0 \\
Psychiatric treatment & $5(2.7)$ & $6(5.9)$ \\
Total responses & $184(100)$ & $102(100)$ \\
Total subjects & 56 & 28 \\
\hline
\end{tabular}

* Collected using the sociodemographic questionnaire.

Table 5 - Analysis of Reasons for Hospitization, by Adverse Events

\begin{tabular}{|c|c|c|c|c|c|}
\hline Hospitalization reason & Birthdays & $\begin{array}{c}\text { Traumatic } \\
\text { memory/fight }\end{array}$ & $\begin{array}{c}\text { Stressful } \\
\text { event }\end{array}$ & Holidays* & Total $^{+}$ \\
\hline SA & $6(60)$ & $0(0)$ & $0(0)$ & $5(50)$ & 10 \\
\hline Accident (traffic/work/domestic) & $12(75)$ & $0(0)$ & $1(6.3)$ & $5(31.3)$ & 16 \\
\hline Illness & $6(66.7)$ & $2(22.2)$ & $2(22.2)$ & $0(0)$ & 9 \\
\hline Assault & $4(100)$ & $0(0)$ & $0(0)$ & $0(0)$ & 4 \\
\hline Total $^{\ddagger}$ & 28 & 2 & 3 & 10 & 39 \\
\hline
\end{tabular}

* Easter, Christmas, New Year, Carnival.

+ Total number of people

* Total number of responses. 


\section{Discussion}

This study evaluated situations of childhood trauma, social support, sociodemographic aspects, and loss of parents during childhood or recent losses. Suicide attempt, as a bid to end one's life, is considered a matter of public health. ${ }^{3}$ With that in mind, this research was conducted to evaluate suicide attempt in patients who were seen in the emergency room or needed admission or medical care at the Hospital de Pronto Socorro, in Porto Alegre, Brazil.

In the course of normal human development, all people may face traumatic events inherent to life. However, traumatic events can occur that exceed children's capacity to understand and then become etched on their minds. Occasions that trigger trauma leave painful marks in the psychic apparatus. Such traumatic experiences are continually relived through memories and, depending on the intensity, they can become overpowering in a person's life, causing mental disorder, suicide attempt, and completed suicide. Psychic pain can seriously damage human development, impairing cognitive and emotional development, and leading people to commit violent acts of self-harm. ${ }^{18}$

In the suicide attempt sample collected at the HPS, $28 \%$ of the participants wrote some kind of suicide letter or sent messages through smartphone apps, i.e., they sought to express their unbearable psychic pain. In many cases, suicide attempt is founded on an absence of psychic resources capable of containing the psychic pain. ${ }^{18}$

The results of the instrument for measuring social support for the sample as a whole showed that the mean number of relatives considered socially supportive was 3.4 ( $S D=3.3$ ), while the mean number of close friends was 1.9 ( $S D=2.8)$. The sum of the mean numbers of relatives and close friends was higher for the control group (6.6) than for the case group (2.5) ( $p<0.001)$. In other words, patients in the control group had more social support and were more likely to be active and interactive in their social environments.

We sought to understand whether support from family or close friends would protect against suicide risk. As mentioned above, having one additional relative and/or close friend lowered suicide risk by $24 \%$ and one extra point of instrumental support reduced risk by $80 \%$. One extra point of affectionate support gave $69 \%$ protection against risk of suicide attempt, one point of emotional support gave 55\% ( $p<0.001)$, and one point of informational support gave $71 \%$ protection $(p<0.001)$. Combining affectionate support and informational support resulted in $63 \%$ protection $(p<0.001)$.
The authors of a study conducted to test the construct validity of the MOS stated that there was a positive association between relatives and close friends and emotional support/social companionship. Compared to those who reported having no close friends or relatives, the likelihood of perceiving strong support was around three times higher ( $\mathrm{OR}=3.3 ; 95 \% \mathrm{CI}: 2.2-4.9)$ for those who had one to two friends and about 10 times higher $(\mathrm{OR}=10.3 ; 95 \% \mathrm{CI}: 6.9-15.4)$ for those who reported eight or more friends. ${ }^{10}$ However, a recent study by Zatti et al. ${ }^{19}$ with patients who attempted suicide found that the sample had severe symptoms of depressive disorder and social support rejection. The researchers calculated Pearson coefficients for correlations between the variable depressive disorder and the MOS dimensions and found significant and inverse relationships with tangible support, emotional support, social interaction, and emotional support; in other words, the higher the score for depressive disorder, the lower the scores for the MOS dimensions. ${ }^{19}$

Certain crises, such as vital (aging) and circumstantial (unexpected events), for example, may lead to what Botega ${ }^{20}$ calls existential collapse. This collapse generates anguish, helplessness, incapacity, burnout, and lack of prospects for solutions and may increase vulnerability to suicide, which begins to seem like a solution for the unbearable pain. ${ }^{20}$ We investigated whether such existential collapse can be triggered by anniversaries or special dates that bring back memories or whether such dates can become overwhelming due to the individual having suffered intensely, such as feeling abandoned, helpless, and lacking prospects. We analyzed the suicide attempt cases and obtained 11 positive answers for 11 anniversaries (including birthdays) and/or special dates: $54.5 \%$ (6 events) related to anniversaries and $45.5 \%$ ( 5 events) related to holidays. The feeling of abandonment or loneliness is often experienced in early childhood. In the analysis of loss of a significant other during childhood among subjects who had attempted suicide, 68\% ( $p<0.001)$ indicated that they had lost a significant other during childhood. This figure serves as an alert for existential crises.

Based on the above, some factors are associated with increased suicide risk: suicidal thoughts, mental disorder, physical diseases, childhood trauma, psychosocial issues, and psychological and demographic aspects. ${ }^{21}$ Our research findings are in line with these factors, since the prevalence of a previous psychiatric medical record was lower in the control group (7\%) than in the case group $(63.4 \%)(p<0.001)$.

Concerning clinical implications, patients with these disorders and a record of childhood trauma must be 
carefully evaluated for suicide risk as well as for impulsive and aggressive tendencies, which must be treated during mental health care follow-up with the aim of preventing suicidal behavior. ${ }^{22}$

This study also investigated whether the patients had a history of disorders within their immediate families, and the most prevalent conditions reported were depressive disorder and alcoholism. During data collection, some histories appeared to show symptoms of trauma and suffering dating back to childhood that had been caused by witnessing constant fights/arguments within the immediate family, because of constant use of alcohol by caregivers. Adverse situations experienced during childhood, such as sexual, physical, and psychological abuse, as well as physical and emotional neglect, are strong risk factors for many of the main causes of psychic suffering, death, diseases, and incapacitation in all phases of development. ${ }^{23,24}$

Effective interventions are needed to prevent mistreatment in childhood and it is important that such services are available for young people who may be at increased risk for suicide, given their prior history. ${ }^{25}$ Studies state that the CTQ is an appropriate tool for retrospective measurement and evaluation of previous trauma in adolescents and adults. ${ }^{10}$ The estimates observed in our study showed that means for the case group were always higher than those for the control group. Emotional abuse and emotional neglect, in that order, were the variables with the highest differences between the two groups (differences of 5.3 and 5.1 respectively).

Studies that evaluated CTQ comparing cases with suicide attempt and controls without suicide attempt have shown that CTQ mean scores are higher in suicide attempt cases than in controls. ${ }^{25}$ Analysis of childhood abuse results in our sample showed that women had higher means than men for the following variables: emotional abuse ( $p<0.001)$, physical abuse $(p=0.020)$, sexual abuse $(p=0.037)$, and emotional neglect $(p<0.001)$. Results from several small studies across the world reveal alarming data concerning the level of abuse against women, beginning in childhood, as we can confirm. 8,24

The ARYS (At Risk Youth Study) collected data in Canada from 2005 to 2013. The street youths from this prospective cohort study were aged between 14 and 26 years and were involved with drugs and street life. Participants responded to the CTQ and, using the Cox regression model, the study examined associations between five types of mistreatment and suicide attempt, concluding that childhood mistreatment is associated with higher risk of suicidal behavior among youths. ${ }^{26}$ Our study also corroborates these results, since childhood traumas were statistically significant in our case group.

The presence of childhood mistreatment was strongly associated with risk of suicide attempt. Subjects who had a history of previous physical abuse, emotional abuse, or emotional neglect were 3 to 5 times more likely to report a suicide attempt. When examined in a combined statistical model, only physical abuse maintained an independent effect on risk of suicide attempt. Sexual abuse was the least common childhood trauma among those reported in this study. However, the authors did not rule out the possibility that the participants felt uneasy about communicating such experiences. ${ }^{26}$ This corroborates our findings, since sexual abuse was the least common childhood trauma reported: only one person replied "always" to all of the assertions related to sexual abuse in the CTQ.

In a longitudinal study that followed 183 youths who had suffered sexual abuse for 9 years, analysis showed that the risk of suicide was 13 times higher than that observed in the general population. ${ }^{27}$ Studies of childhood abuse and suicidal behavior state that the risk of suicidal behavior increases according to the intensity of the abuse during childhood. ${ }^{28,29}$

Forty-three participants answered a parallel investigation about events, memories, or birthdays/ anniversaries/important dates and $65 \%$ of them ( $n$ $=28$ ) had an admission date near a birthday (the patient's own or that of a significant family member). These data expose unconscious aspects involved in traffic accidents and bias in suicide attempts concealed in traffic accidents, and thus not considered suicide attempts, since the majority of people in the group were admitted due to the former. ${ }^{30}$ Traffic accidents concern authorities throughout the world, given the number of people involved in fatal events of this kind. The victims might be indulging a desire for competition, speed, and living dangerously, poised between life and death. ${ }^{31,32}$ The relationship between admission and commemorative dates suggests unconscious aspects to be analyzed. In short, we could suppose that presenting suicidal behavior or suicide risk represents sadistic fury against oneself. One of the limitations of this study is the number of participants, which prevents us from proposing generalizations.

Pompili conducted a bibliographic search on PubMed and PsycInfo for publications from 1955 to 2011 that reported evidence of a connection between drivers involved in traffic accidents and suicidal behavior. ${ }^{33,34}$ Some scientists emphasize that the suicidal motivations or self-destructive impulses in traffic accidents are unconscious. ${ }^{30,35}$ According to one estimate, by the year 2030, injuries caused by traffic accidents will be the 
fifth largest cause of death in the world. However, the phenomenon is most often reported as an accidental act in national statistics. ${ }^{33}$

In the conclusions to a meta-analysis of longitudinal studies from the last decade, Zatti et al. ${ }^{4}$ compared people who were exposed to traumatic events in childhood with the general population, showing that they are at increased risk of SA. Since the various forms of childhood trauma are preventable, there are strong reasons for governments to invest in programs, policies, and interventions to minimize childhood exposure to sources of severe adversity. ${ }^{4}$

\section{Conclusion}

The results of this study show that situations of abuse or neglect provoke unbearable psychic pain, many times impairing reality test performance. Such 'echoes' inside the individual may provoke a desire to interrupt life by ending it.

The results of this study suggest that a combination of factors, such as childhood trauma, lack of social support, and history of psychiatric diseases in the immediate family, are involved in risk of suicidal behavior. The profile of the patients who attempted suicide was associated with a history of psychiatric problems and physical/emotional abuse and neglect in childhood. Additionally, SA was associated with lower means in all domains of social support and with history of childhood loss. It is on these elements that we must focus attention, prevention, and intervention.

Finally, both the literature reviewed and the results of this study indicate that preventive and therapeutic measures act as key factors in reducing risk of suicide when administered to people who have suffered mistreatment during childhood development. The same preventive care is applicable when increased transgenerational selfdestructive tendencies are observed.

\section{Acknowledgements}

This study was part financed by the Coordenação de Aperfeiçoamento de Pessoal de Nível Superior (CAPES; Finance Code 001), the Fundação Instituto de Pesquisas Econômicas (grant 150267), and the Fundo de Incentivo a Pesquisa - Hospital de Clínicas de Porto Alegre (FIPEHCPA), Porto Alegre, RS, Brazil. We are grateful to the patients who were willing to participate in our research, to the Hospital de Pronto Socorro, and to the Hospital de Clínicas of Porto Alegre for their support in making this study possible.

\section{Disclosure}

No conflicts of interest declared concerning the publication of this article.

\section{References}

1. World Health Organization. Child maltreatment [Internet]. 2014 [cited 2018 Jan 5]. http://www.who.int/mediacentre/factsheets/ fs150/en/

2. Souza F. Suicídio - dimensão do problema e o que fazer? Rev Debates Psiquiatr. 2010;5:6-8.

3. Wilcox HC, Wyman PA. Suicide prevention strategies for improving population health. Child Adolesc Psychiatr Clin N Am. 2016;25:219-33.

4. Zatti C, Rosa V, Barros A, Valdivia L, Calegaro VC, Freitas $\mathrm{LH}_{\text {, }}$ et al. Childhood trauma and suicide attempt: A meta-analysis of longitudinal studies from the last decade. Psychiatry Res. 2017;256:353-8.

5. Araújo RMF. Mais do que palavras: a associação do abuso emocional na infância com o comportamento suicida [dissertation]. Porto Alegre: Pontífícia Universidade Católica do Rio Grande do Sul; 2015.

6. Fonseca DL. Apoio social e eventos estressantes em pacientes atendidos por tentativas de suicídio em uma grande emergência do Rio de Janeiro [dissertation]. Rio de Janeiro: Universidade Federal do Rio de Janeiro; 2009.

7. Roy A. Combination of family history of suicidal behavior and childhood trauma may represent correlate of increased suicide risk. J Affect Disord. 2011;130:205-8.

8. Grassi-Oliveira R, Stein LM, Pezzi JC. Tradução e validação de conteúdo da versão em português do Childhood Trauma Questionnaire. Rev Saude Publica. 2006;40:249-55.

9. Bernstein DP, Stein JA, Newcomb MD, Walker E, Pogge $D$, Ahluvalia T, et al.. Development and validation of a brief screening version of the Childhood Trauma Questionnaire. Child Abuse Negl. 2003; 27:169-90.

10. Grassi-Oliveira R, Cogo-Moreira $H$, Salum JA, Brietzke E, Viola TW, Manfro GG, et al. Childhood Trauma Questionnaire (CTQ) in Brazilian samples of different age groups: Findings from confirmatory factor analysis. PLoS One. 2014;9:e87118.

11. Sherbourne CD, Stewart AL. The MOS social support survey. Soc Sci Med. 1991;38:705-14.

12. Griep Rh, Chor D, Faerstein E, Lopes C. Apoio social: confiabilidade teste-reteste de escala no Estudo Pró-Saúde. Cad Saude Publica. 2003; 19:625-34.

13. Griep RH, Chor D, Faerstein E, Lopes C. Confiabilidade testereteste de aspectos da rede social no Estudo Pró-Saúde. Rev Saude Publica. 2003;37:379-85.

14. Griep RH. Confiabilidade e validade de instrumentos de medida de rede social e de apoio social utilizados no Estudo Pró-Saúde [doctoral thesis]. Rio de Janeiro: Escola Nacional de Saúde Pública, Fundação Oswaldo Cruz; 2003.

15. Griep RH, Chor D, Faerstein E, Werneck GL, Lopes CS. Validade de constructo de escala de apoio social do Medical Outcomes Study: adaptada para o português no Estudo Pró-Saúde. Cad Saude Publica. 2005;21:703-14.

16. Amorim P. Mini International Neuropsychiatric Interview (MINI): validação de entrevista breve para diagnóstico de transtornos mentais. Braz J Psychiatry. 2000;22:106-15.

17. Hair JR, Black WC, Babin BJ, Anderson REE, Tatham RL. Análise multivariada de dados. 6a ed. Porto Alegre: Bookman; 2009.

18. Macedo MMK, Werlang BSG. Tentativa de suicídio: o traumático via ato-dor. Psicol Teor Pesq. 2007;23:185-94.

19. Zatti C, Guimarães LSP, Soares MA, Neves J, Santana MRM, Calegaro V, et al. Relación entre apoyo social y trastornos mentales en pacientes ingresados por intento de suicidio en un hospital de emergencia. Acta Psiquiatr Psicol Am Lat. 2018;64:261-72.

20. Botega NJ. Crise suicida: avaliação e manejo. Porto Alegre: Artmed; 2015.

21. Neves F, Corrêa H, Nicolato R. Suicídio: propostas de serviços e ações a serem executadas. Rev Psiquiatr Hoje. 2010;5:36-40

22. Park S, Hong JP, Jeon HJ, Seong S, Cho MG. Childhood exposure to psychological trauma and the risk of suicide attempts: the 
modulating effect of psychiatric disorders. Psychiatry Investig. 2015; 12:171-6.

23. Spinhoven P, Elzinga BM, Van-Hemert AM, Rooij M, Penninx PW. Childhood maltreatment, maladaptive personality types and level and course psychological distress: a six-year longitudinal study. J Affect Disord. 2016;191:100-8.

24. Viola TW, Salumb GA, Kluwe-Schiavona B, Sanvicente-Vieira B, Levandowskia ML, Grassi-Oliveira R. The influence of geographical and economic factors in estimates of childhood abuse and neglect using the Childhood Trauma Questionnaire: a worldwide metaregression analysis. Child Abuse Negl. 2016;51:1-11.

25. Hadland SE, Marshall BDL, Kerr T, Qi J, Montaner JS, Wood E. Suicide and history of childhood trauma among street youth. J Affect Disord. 2012;136:377-80.

26. Hadland SE, Wood E, Dong H, Marshall BDL, Kerr T, Montaner JS, et al. Suicide attempts and childhood maltreatment among street youth: a prospective cohort study. Pediatrics. 2015;136:440-9.

27. Plunkett A, O'toole B, Swanston $H$, Oates RK, Shrimpton S, Parkinson P. Suicide risk following child sexual abuse. Ambul Pediatr. 2001;1:262-6.

28. Lopez-Castroman J, Jaussent I, Beziat S, Guillaume S, BacaGarcia E, Olié E, et al. Posttraumatic stress disorder following childhood abuse increases the severity of suicide attempts. ] Affect Disord. 2015; 170:7-14.
29. Devries KM, Mak JYT, Child JC, Falder G, Bacchus LJ, Astbury J, et al. Childhood sexual abuse and suicidal behavior: a metaanalysis. Pediatrics. 2014;133:e1331-44.

30. Lima KC, Pinho MX. Suicídio e ato falho: considerações psicanalíticas acerca de suicídios acidentais. Rev ConScientiae Saude. 2010;9:139-45.

31. Botega NJ. Comportamento suicida: epidemiologia. Psicologia USP. 2014;25:231-6.

32. Menninger KA. Purposive accidents an expression of selfdestructive tendencies. Int J Psychoanal. 1936;18:6-16.

33. Pompili M, Serafini G, Innamorati M, Montebovi $F$, Palermo M, Campi S, et al. Car accidents as a method of suicide: a comprehensive overview. Forensic Sci Int. 2012;223:1-9.

34. Pompili M, Girardi P, Tatarelli G, Tatarelli R. Suicidal intent in single-car accident drivers: review and new preliminary findings. Crisis. 2006;27:92-9.

35. Selzer L, Payne CE. Automobile accidents, suicide and unconscious motivation. Am J Psychiatry. 1962;119:237-40.

\section{Correspondence:}

Cleonice Zatti

Rua Ramiro Barcelos, 2400, $2^{\circ}$ andar, Bairro Santana

90035-003 - Porto Alegre, RS - Brazil

E-mail: cleonice.zatti@outlook.com 